$$
\begin{array}{r}
\text { B18110 :CA } \\
\text { SETORE HOS OCULTURA } \\
\text { ESALO OSP }
\end{array}
$$

\title{
EFEITOS DE REGULADORES VEGETAIS NA PRODUTIVIDADE DO TOMATEIRO *
}

\author{
PAULO R.C. CASTRO** \\ JOSE C. PASTORE **

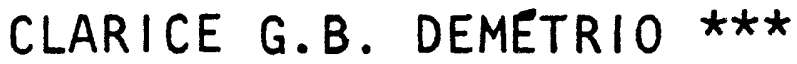

\section{RESUMO}

Estudaram-se em condições de casa de vegetação, os efeitos de reguladores vegetais no peso, número e peso médio dos frutos de tomateiro (Lycopersicon esculentum Mill.l. Cloreto (2-cloroetil) trimetilamônio (CCC) $1.000 \mathrm{ppm}$ e àcido succínico-2,2-dime tilhidrazida (SADH) $2.000 \mathrm{ppm}$ foram aplicados antes da abertura floral e duas semanas depois, äcido 3-clorofe noxipropiônico (Fruitone-CPA) 50 ppm pulverizado 4 semanas após a antese das primeiras flores e ácido $\mathrm{N}$-ace-

* Entregue para publicação em 14/05/1282.

** Departamento de Botânica, E.S.A. "Luiz de Que irōz", USP.

*** Departamento de Matemática e Estatística, E.S.A. "Luiz de Queiroz", USP. 
til tiazolidin-4-carboxilico com äci do fölico (Ergostiml $0,75 \mathrm{ml} / 1$ apli= cado durante a antese das primeiras flores dos 3 cachos. Observou-se que - SADH reduziu o peso, número e peso médio dos frutos de tomateiro. Ergos tim diminuiu o peso total e o peso médio dos frutos produzidos. Aplica ção de Fruitone-CPA mostrou uma tendência de aumentar o peso total e 0 nümero de frutos colhidos.

INTRODUÇÃO

Os efeitos de reguladores vegetais em tomateirotêm mostrado que esta planta responde efetivamente a estes compostos químicos, poucos trabalhos porém, apresentaram aumentos na produção de frutos.

Por tratar-se de uma cultura em que se utilizamtéc nicas culturais avançadas, o uso de reguladores vegetais poderá vir a ser a próxima etapa para obtenção de aumentos efetivos na produtividade.

AROMOV (1978) realizou tratamento com chlormequat (CCC) 0,03 e $0,05 \%$ no momento do transplante de tomate iros. Observou a produção de plantas compactas, mais ade quadas para o plantio mecanizado. Verificou aumento ná porcentagem de sobrevivência e maiores produções nas plan tas tratadas com CCC.

PISARCZYK \& SPLITTSTOESSER (1979) notaram que daminozida, chlormequat e ethephon, aplicados em tomateiros no estágio de duas folhas verdadeiras, retardaram o crescimento das plântulas por duas semanas. Ethephon atrasou a florescência das plantas transplantadas para condições de campo. Ethephon e chlormequat não afetaram as produções dos tomateiros. Daminozida 10.000 ppm aumentou o número de frutos por planta. 
CASTRO \& MALAVOLTA (1976) não observaram variações no número ou peso dos frutos obtidos de tomateiros tratados com CCC e SADH.

READ \& FIELDHOUSE (1970) verificaram aumento na produção de frutos em tomateiros tratados com ácido succínico-2,2-dimetilhidrazida (SADH) 2.500 ppm no estägio de la ou 4 a folha verdadeira.

YOUNIS \& EL-TIGANI (1977) não notaram aumento na fi xação de frutos em tomateiros tratados com SADH, sendo que READ \& FIELDHOUSE (19.70) observaram que SADH 5.000 ppm pode ser aplicado para cessar a produção de frutos do tomate iro.

ANONIMO (1975) verificou que a pulverização com Fruitone-CPA promoveu aumento na produção de frutos em tomateiro 'Rutgers'. Observou que o peso médio dos frutos era de 88,131 e $133 \mathrm{~g}$, nos tratamentos controle, Fruitone-CPA 500 e 50 ppm, respectivamente.

ANONIMO (1277) considerou que os melhores resultados com Ergostim em tomateiro podem ser obtidos com apli cação de 0,5 a $1 \mathrm{ml}$ do produto/l de ägua em três vezes, com intercalos de 12 dias, correspondente ao início da florescência dos três primeiros cachos.

LUKASIK (1977) efetuou a pulverização de tomateiros com metil-cloroflurecol 0,25 ppm durante a florescên cia dos primeiros 2 ou 3 cachos. 0 tratamento aumentou a precocidade, produção comercial e total de frutos. Os frutos individuais das plantas tratadas mostraram-se mais pesados em relação ao controle.

0 presente ensaio foi efetuado com o objetivo de de terminar a ação do CCC, SADH, Frui tone-CPA e Ergostim nā produtividade do tomateiro.

MATERIAIS E METODOS

o experimento, realizado em condições de casa de ve 
getação, foi iniciado em 1 de março de 1980, com a semea dura do tomateiro (Lycopersicon esculentum Mill. Lem ca $\bar{i}$ $x a$ de madeira contendo solo esterelizado. 0 transplanté foi efetuado em 13/03/80 para vaso de cerâmica com 14 li tros de capacidade total contendo 12 litros de terra. Co locaram-se três plântulas por vaso, tendo-se realizado 0 desbaste de duas delas em 28/03/80, para se obter maior uniformidade. Utilizaram-se os tratos culturais normal mente empregados para a cultura.

Além do tratamento controle, aplicou-se cloreto (2cloroeti i) trimetilamônio (CCC) 1.000 ppm e ácido succínico-2,2-dimetilhidrazida (SADH) 2.000 ppm antes da aber tura floral $(10 / 04 / 80)$ e duas semanas depois $(24 / 04 / 80)$, ácido 3-clorofenoxipropiônico (Fruitone-CPA) 50 ppm 4 se manas após a antese das primeiras flores (12/05/80) e bio estimulante formado de äcido $\mathrm{N}$-acetil tiazolidin-4-carbo xílico e ácido fölico (Ergostim) $0,75 \mathrm{ml} / 1$ em pulverização durante a antese das primeiras flores dos 3 cachos $(14 / 03,28 / 04$ e 12/05/80).

0 delineamento experimental empregado foi inteiramente casualizado com 10 repetições, tendo-se mantido uma planta por vaso e por repetição. Procedeu-se a comparação de médias pelo teste Tukey, calculando-se a diferença mínima significativa (D.M.S.) ao nivel de $5 \%$ de proba bilidade.

Determinou-se o número de frutos produzidos, o peso total e o peso médio dos frutos colhidos semanalmente de 26/05 a 02/07/80. Os dados foram transformados em raiz quadrada para efeito de anālise.

\section{RESULTADOS E DISCUSSÃO}

De acordo com a Tabela l, verificamos que o tratamento com SADH reduziu significativamente o número de fru tos produzidos pelo tomateiro em relação ao controle $\bar{e}$ aos demais tratamentos. READ \& FIELDHOUSE (1970) também 


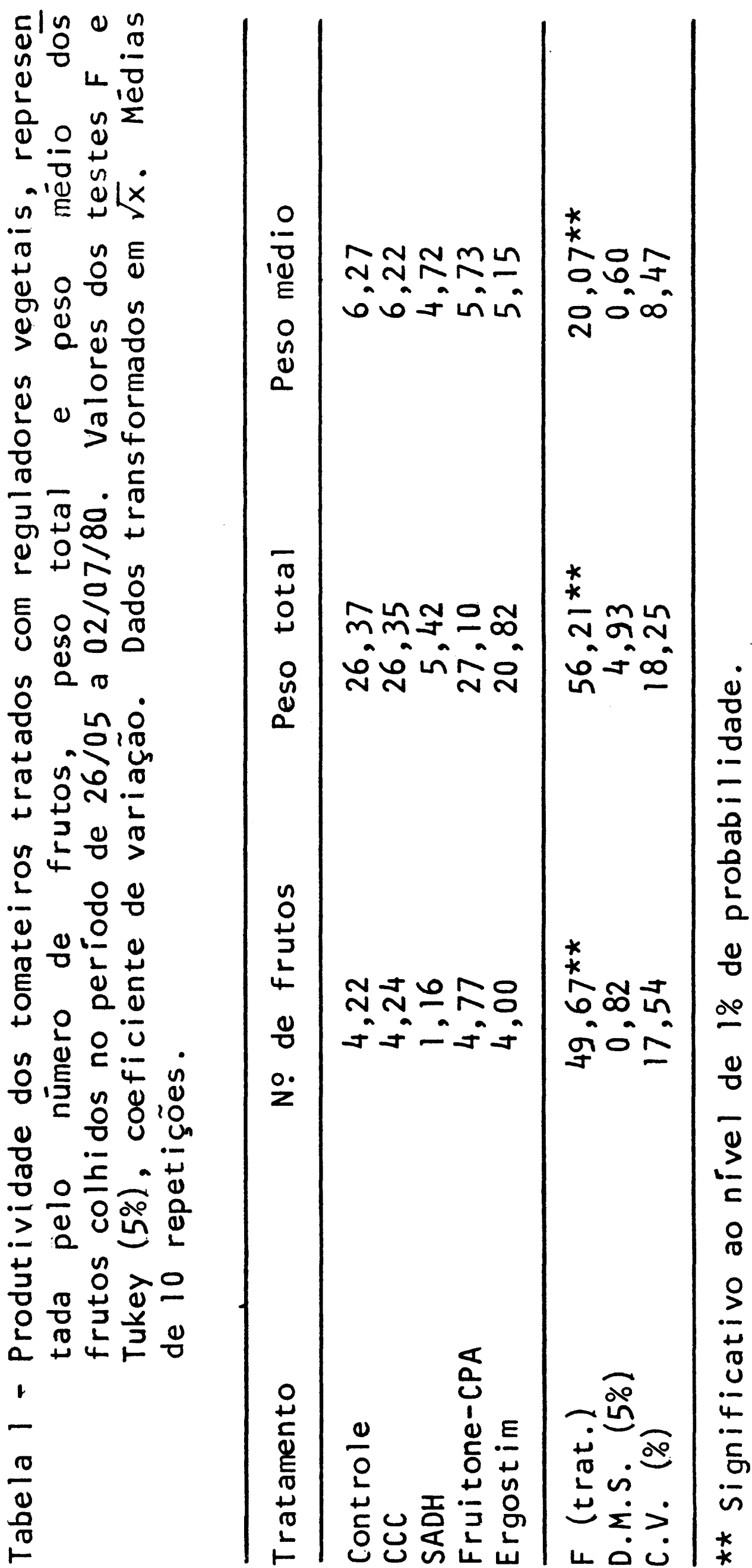


observaram que o SADH pode reduzir sensivelmente a produ ção de frutos do tomateiro.

Aplicação de SADH e Ergostim reduziram o peso total de frutos colhidos dos tomateiros em relação aos tra tamentos com CCC e controle. Estes resultados não estão de acordo com aqueles obtidos por CASTRO \& MALAVOLTA (1976) e ANONIMO (1977). Fruitone-CPA promoveu aumento no peso total dos frutos com relação aos tratamentos com SADH e Ergostim. Aumento na produção de frutos em to mateiros tratados com Fruitone-CPA foi também observado por ANONIMO (1975). Aplicação de SADH reduziu o peso to tal dos frutos em comparação com Ergostim, segundo a tabela 1. READ \& FIELDHOUSE (1970) também notaram diminuição no peso total de frutos produzidos em tomateiros pulverizados com altas concentrações de SADH.

Verificou-se que os tratamentos com SADH e Ergostim promoveram redução no peso médio dos frutos colhidos com relação aos tratamentøs com CCC e controle. Aplicação de SADH reduziu o peso médio dos frutos em relação a Fruitone-CPA (Tabela 1). READ \& FIELDHOUSE (1970) obser varam que 'o SADH pode inibir a fixação dos frutos de tō mateiro de maneira significativa.

CONCLUSOES

Dos resultados obtidos neste ensaio, podemos estabelecer as conclusões:

a) àcido succínico-2,2-dimetilhidrazida $2.000 \mathrm{ppm}$, em duas aplicações em pré e pós - florescência, reduz o número, peso total e peso médio dos fru tos de tomateiro;

b) Ergostim $0,75 \mathrm{ml} / 1$, aplicado na antese floral dos três cachos, diminue o peso total e peso mé dio dos frutos produzidos; 
c) àcido 3-clorofenoxipropiônico $50 \mathrm{ppm}$, pulveriza do 4 semanas após a antese das primeiras $\mathrm{flo}^{-}$ res, mostra uma tendência de aumentar o número e o peso total dos frutos de tomateiro.

\section{SUMMARY \\ EFFECTS OF PLANT REGULATORS ON THE PRODUCTIVITY OF TOMATO PLANTS}

This research deals with the effects of exogenous growth regulators on fruiting of tomato plants (Lycopersicon esculentum Mill.l under greenhouse conditions. Applications of (2-chloroethyl) trimethylammonium chloride (CCC) 1,000 ppm, succinic acid-2,2-dimethylhydrazide (SADH) 2,000 ppm, 3-chlorophenoxy propionic acid (3CP) $50 \mathrm{ppm}$, thiazolidin-4-carboxylic acid plus folic acid $0,75 \mathrm{ml} / 1$, and water (check treatment) were performed. It was observed that SADH reduced total weight, number and weight average of tomato fruits, because of flower abscission caused by the timing of the repeated application. Thiazolidin-4-carboxylic acid plus folic acid reduced the total weight and weight average of tomato fruits. Application of 3-CP showed a tendency to increase total weight and number of fruits in the plant.

\section{LITERATURA CITADA}

ANONIMO, 1975. Experimentos com Fruitone-CPA, Amchem do Brasil, São Paulo, $4 p$.

ANONIMO, 1977. Relatório sobre Ergostim, Montedison, Di visione Agricoltura, Roma, $21 \mathrm{p}$.

AROMOV, M. Kh., 1978. The effect of TUR on transplant qua $1 \mathrm{ity}$ and production of mechanically-planted tomato cuI tivars. Materialy Resp. Shkoly-Seminara 47-53. 
CASTRO, P.R.C.; MALAVOLTA, E., 1276. Efeitos de reguladores de crescimento na frutificação do tomateiro cul tivar Miguel Pereira. An. Esc. Sup. Agr. "Luiz de Que iroz" 33: 201-210.

LUKASIK, S., 1977. (Methy1-2-Cloro-2-Hydroxyfluoren-(9) - Carboxylat) in Form der Blattspritzung auf den Ertrag von Tomaten. Archiv. fur Gartenbau 25: 61-65.

PISARCZYK, J.M.; SPLITTSTOESSER, W.E., 1979. Response of tomato to pre-transplanting applications of chiormequat, daminozide, and ethephon. HortScience 14: 263264.

READ, P.E.; FIELDHOUSE, D.J., 1970. Use of growth retar dants for increasing tomato yields and adaptation for mechanical harvest. J. Amer. Soc. Hort. Sci. 95: 7378.

YOUNIS, M.E.; EL-TIGANI, S., 1977. Comparative effects of growth substances on the growth, flowering and fruiting of tomato plants. Acta Agronomica Academiae Scientiarum Hungaricae 26: 89-103. 